\title{
Forest Protection and Permanence of Reduced Emissions
}

Margaret McCallister, Andrey Krasovskiy, Anton Platov, Alexander Golub, Breno Pietracci and Gabriela Leslie 


\section{About Environmental Defense Fund}

Guided by science and economics, Environmental Defense Fund (EDF) tackles our most urgent environmental challenges with practical solutions. EDF is one of the world's largest environmental organizations, with more than 2.5 million members and a staff of 700 scientists, economists, policy experts and other professionals around the world.

\section{EDF Economics Discussion Paper series}

EDF Economics Discussion Papers represent unrefereed works-in-progress by researchers who are solely responsible for the content and any views expressed therein. Any comments on these papers are welcome and should be sent to the author(s) by email. EDF's Office of the Chief Economist manages the series.

\section{Sharing our Discussion Papers}

Our Discussion Papers (the "Materials") are available for sharing and adaptation under an Attribution-NonCommercial-NoDerivatives 4.0 International (CC BY-NC-ND 4.0) license (the "License"). You can copy and redistribute the Materials in any medium or format; provided, however: (i) you must give appropriate credit to us through recognition of our authorship of the Materials (generally by citing to the Materials); (ii) you must provide the link to the License as per the below; (iii) if you remix, transform, or build upon the Material, you may not distribute the modified Material without our prior written consent; (iv) you may not apply any additional restrictions to any third party that you distribute the Material to other than as specified herein, except that you may not permit any third party to remix, transform or build upon the Materials, without our prior written consent; and (v) you may not reproduce, duplicate, copy, distribute, transmit, sell, trade, resell or exploit for any commercial purpose any portion of the Materials. Images, trademarks, service marks, logos and icons used in the Materials are our property and may not be used without our prior written consent. License information can be found by visiting: https://creativecommons.org/licenses/by-nc-nd/4.0

(C) 2021 Environmental Defense Fund. All rights reserved. 


\title{
Forest Protection and Permanence of Reduced Emissions
}

\author{
Margaret McCallister, ${ }^{\mathrm{a}}$ Andrey Krasovskiy, ${ }^{\mathrm{b}}$ Anton Platov, ${ }^{\mathrm{c}}$ Alexander Golub ${ }^{\mathrm{d}}$, \\ Breno Pietraccie and Gabriela Leslie ${ }^{f}$
}

\footnotetext{
a Corresponding Author: Environmental Defense Fund, 257 Park Ave S, New York, NY 10010, margaretamccallister@gmail.com

b International Institute for Applied Systems Analysis (IIASA), Schlossplatz 1, Laxenburg, A-2361, Austria, krasov@iiasa.ac.at

c International Institute for Applied Systems Analysis (IIASA), Schlossplatz 1, Laxenburg, A-2361, Austria, platovmm@mail.ru

d American University, 4400 Massachusetts Ave NW, Washington, DC 20016, agolub@american.edu

e Environmental Defense Fund, 257 Park Ave S, New York, NY 10010, bpietracci@edf.org

f Environmental Defense Fund, 257 Park Ave S, New York, NY 10010, gleslie@edf.org
}

\begin{abstract}
Tropical forests are essential for climate change mitigation. As awareness grows over the use of credits from reduced emissions from deforestation and forest degradation (REDD+) and other nature-based climate solutions within both voluntary and compliance carbon markets, key concerns about the long-term durability of the reductions, or their permanence, arise for countries, corporations, regulators and policy makers. The paper seeks to analyze an efficient means of distribution and application of different policy pathways to slow down and stop deforestation and explore the longevity of reductions via modeling. The impact of policies like REDD+ most likely will have a time limitation. At some point tropical nations will take more responsibility to protect forests. REDD+ should constitute an initial intervention that will help tropical nations shock to a zero-deforestation trajectory.

To establish conditions of permanence, we conduct numerical analyses using a model based on a cellular automata algorithm that learns from historical deforestation patterns and other spatial features in the Brazilian state of Mato Grosso. The model simulates future deforestation, first applying policy to reduce deforestation and then relaxing the policy intervention.

Our simulations show that policies that are successful in reducing deforestation and related emissions from business as usual may have long-term positive consequences on an avoided deforestation trajectory even after potential policy reversals. Some accumulated gains could be lost but sizable benefits will remain, assuring permanence of emissions reduction during the
\end{abstract}


policy implementation and potentially even after policies are relaxed. Hence, permanence depends both on the probability of policy reversals and the risk of emissions rebounding. Our results are important for advancing the understanding around the unsettled debate on the permanence of avoided emissions. Further, this paper argues that as policies to prevent deforestation or reduce emissions otherwise are reversible, permanence should be understood and discussed in a probabilistic and time-dependent framework.

\section{Keywords}

Deforestation, REDD+ permanence, jurisdictional approach, machine learning.

\section{JEL classification numbers}

C89, Q23, Q54

\section{Acknowledgments}

This work has been supported by the Norwegian Aid Agency (NORAD) via grant Norad-QZA0464, QZA-16/1218: "Delivering Incentives to End Deforestation: Global Ambition, Private/Public Finance and Zero-Deforestation Supply Chains.”

The research was also supported by the RESTORE+ project (www.restoreplus.org), which is part of the International Climate Initiative (IKI), supported by the Federal Ministry for the Environment, Nature Conservation and Nuclear Safety (BMU) based on a decision adopted by the German Bundestag. 


\section{Contents}

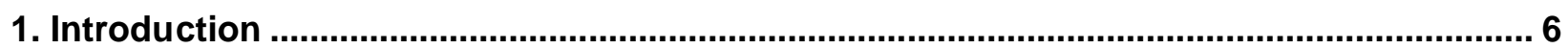

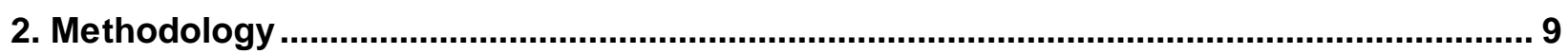

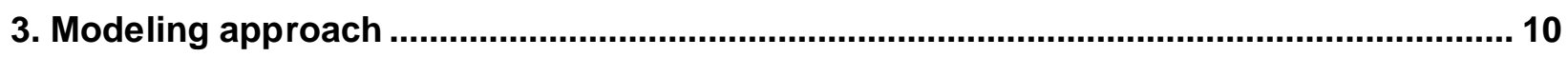

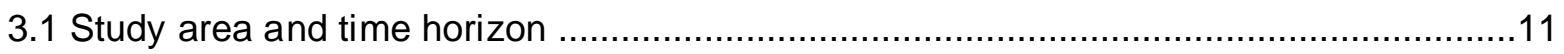

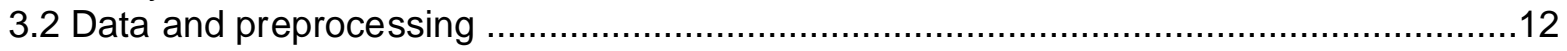

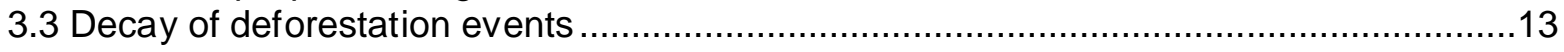

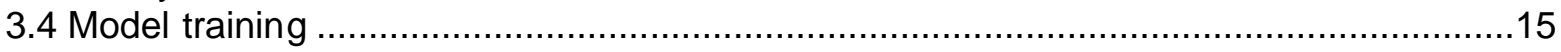

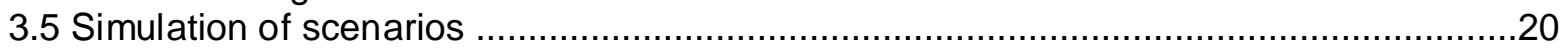

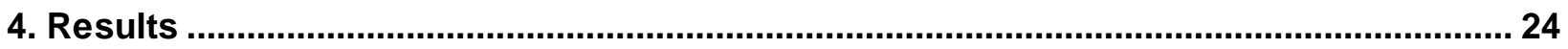

4.1 Centralized scenarios with variable thresholds ................................................25

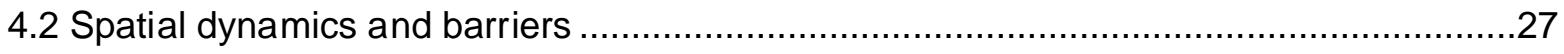

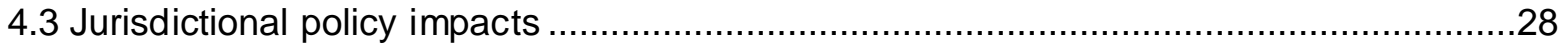

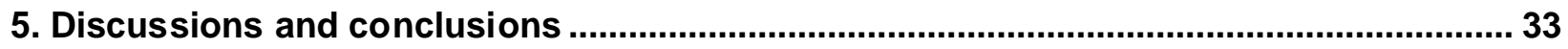

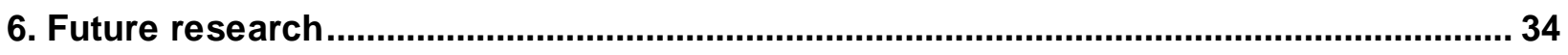

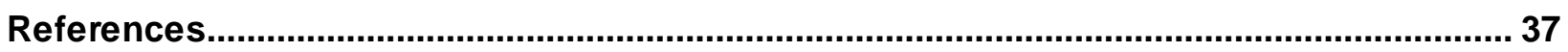




\section{Introduction}

Deforestation accounts for roughly $14 \%$ of annual global greenhouse gas emissions (Harris et al., 2021) and reducing it is essential to any climate change mitigation strategy. Reducing emissions from deforestation and forest degradation (REDD+) plus the sustainable management of forests and the conservation and enhancement of forest carbon stocks is integral to climate change mitigation worldwide.

A recently published study by Fuss et al. (2021) demonstrated significant macroeconomic value of REDD+ at the global level under a policy to stabilize emissions in line with the targets of the Paris Agreement. The paper forecasted REDD+ savings "up to 22\% of the cost of the global climate policy, generating \$30.6 to $\$ 36.4$ trillion in risk-adjusted cost savings.” There are also significant ancillary benefits of avoiding deforestation, but all of that could be harvested only if the reduction of emissions is permanemt.

In order to realize REDD+ gains, it is important to understand the driving forces behind deforestation. Many studies distinguish between proximate/direct causes and underlying/indirect causes of deforestation and forest degradation (e.g., Geist and Lambin, 2002; Kissinger et al., 2012). Proximate causes are those resulting from human activity, such as agricultural expansion or livestock grazing, while underlying causes arise from the social, economic and political systems at work.

Many studies have identified a variety of proximate agents of deforestation and forest degradation. These include livestock production (Müller-Hansen et al., 2019), agricultural expansion (Acheampong et al., 2019; Barbier, 2004), logging (Bowles et al., 1998; Islam and Sato, 2012), mining (Sonter et al., 2017), hydroelectric dams (Chen et al., 2015) and property rights (Mendelsohn, 1994).

Each of these drivers can directly impact deforestation rates. They are easily identifiable and can thus be controlled more readily than some of the broader underlying institutional or economic drivers of deforestation. For instance, one study found that institutional drivers of deforestation in Uganda included "budgetary constraints, corruption, the frequent trading of forests for political capital, and the unfettered growth in the number of districts (stretching already tight resources)" (Tumusiime et al., 2018). Certain studies have explicitly conceded that while institutional factors are important, their actual influence is difficult to quantify (Meyer et al., 2003). 
Another important aspect of forest conservation strategy is ensuring that the mitigation attributed to avoided deforestation is "permanent." The emissions reductions from an avoided deforestation project may not be "permanent" if those reductions are exposed to certain risk factors. Risk factors can be internal or external to the emissions reductions project (Verified Carbon Standard, 2011). If these risk factors are realized, the mitigation can be reversed, thereby negating the mitigation such that it offers only a temporary benefit. Such a reversal makes the emissions reductions associated with the project "non-permanent" as they do not exist in perpetuity. Since it is virtually impossible to guarantee the perpetuity of emissions reductions, most jurisdictional or project-based crediting programs designate a specific time period for which the avoided emissions must be maintained in order to be considered permanent (i.e., 40 years, 100 years, etc.) What's more, research has now revealed that some projects have overstated their baseline emissions reductions with inflated crediting baselines (West at al., 2020).

Internal project risks are inherent to project design and management (Verified Carbon Standard, 2011). These types of risks can be related to project management or financial viability. They can also result from opportunity cost, in which there is a profitable alternative land-use activity where the avoided deforestation emissions reductions project is located. External project risks parallel those underlying risks discussed above. They are externalities outside the control of the project designer or manager, and can take the form of a lack of community engagement or a predisposition to natural disasters, such as wildfires.

With so many drivers of deforestation and risks of non-permanence, it is essential that the government designs effective policy to both combat deforestation and ensure avoided deforestation permanence. Policies are effective in ensuring the permanence of avoided deforestation if they are continually enforced. To envision the effectiveness or lack thereof of a policy, we imagine alternative emissions pathways after the implementation and subsequent rollback of a given policy (Schwartzman et al. 2021, fig. 1, p. 3). At time $\mathrm{T}_{0}$, the policy is implemented and emissions from deforestation begin to decline. However, after a short time the policy is rolled back, at which point we can envision four distinct potential paths with varying associated emissions. Path 1 sees deforestation and its associated emissions continue to decline. Path 2 sees emissions rise slightly but remain below the business as usual (BAU) trajectory prepolicy intervention. In Path 3, emissions return to the BAU trajectory. Finally, in Path 4 emissions exceed the BAU trajectory, with more emissions over time than in the absence of the 
policy. These pathways allow us to examine the cumulative emissions reductions over time associated with each counterfactual scenario following the rollback of a policy.

For numerical analysis we calibrate the model on Mato Grosso data. For the permanence analysis we consider two (carrots-and-sticks) jurisdictional policies. The first simulates a jurisdictional effort to eliminate deforestation in private and public lands. The second simulates full compliance with the 2012 Brazilian Forest Code - i.e., reforestation of all areas within private properties with native vegetation deficits, and avoiding legal deforestation in properties with native vegetation surplus. Both are aimed at generating REDD+ offsets with a time horizon out to 2050.

This paper seeks to analyze an efficient means of distribution and application of different policy pathways to slow down and stop deforestation and explore the longevity of reductions via modeling. Further, it looks at historical deforestation data for the state of Mato Grosso from 2001 to 2016 while controlling for covariates that affect forest clearings -including roads, conservation units and Iindigenous lands, among others - to establish a baseline with which we calibrate our model and the algorithm it uses to replicate historical deforestation. Further, we introduce mechanisms to break trends of historical deforestation and project the aforementioned scenarios. Our model investigates the spatial dependence of deforestation, or how deforested cells impact the behavior of their neighbors. Moreover, the model evaluates spatial correlation to probe for a possible unobserved factor that varies spatially, making it more likely that neighboring cells become deforested. We model increased law enforcement to curb deforestation at a jurisdictional scale to generate REDD+ credits from 2025 to 2034. From 2035 onwards we simulate different scenarios to better understand how potential policy rollbacks would affect permanence of reduced deforestation and emissions. We simulate a continuation of tight law enforcement and different levels of law enforcement loosening by changing the threshold cutoff probabilities at which forest lands are cleared. However, results are applicable to any jurisdictional policy that is limited in time.

The paper is organized as follows. Section 2 details the machine learning and cellular automata methodology employed. Section 3 describes how we applied the cellular automata algorithm to learn from past deforestation patterns and other spatial features (e.g., Indigenous lands), datasets employed, how the model was trained and calibrated, and how simulations were performed. Section 4 presents the simulation results. In Section 5, we discuss our main conclusions and, in Section 6, we discuss future research possibilities. 
Forest Protection and Permanence of Reduced Emissions

\section{Methodology}

Our goal is to develop an illustrative simulation model of deforestation across a landscape that takes into account spatial interactions. The method we use is a particular form of cellular automata (CA). These are spatially and temporally discrete computational systems composed of cells, which evolve in parallel at time steps following dynamic transition rules: the update of a cell state depends on the states of cells in its local neighborhood.

CA is widely used for modeling spatial dynamics, including interactions between neighboring cells. Applications include modeling wildfire spread (Trucchia et al., 2019), propagation of epidemics (Sirakoulis et al., 2000), land-cover change and deforestation (Soares-Filho et al., 2002), and surface water flow (Parsons and Fonstad, 2007).

CA can be continuous or discrete. Using continuous CA, studies model the transition of spatial probabilities of deforestation in the Amazon (Soares-Filho et al., 2002). These studies are based on detailed input datasets, including information on various land-cover classes. Discrete CA has been used for modeling wildfire spread dynamics (Trucchia et al., 2019).

In CA, every cell can represent states of several variables, which in turn interact with one another and are simultaneously subject to the states of other cells. Interaction between cells can be approached in several ways, including implementation of kernels and linear and nonlinear functions. For instance, in modeling epidemic propagation (Sirakoulis et al., 2000) each CA cell represents a fraction of the total population in one of three states: infected, immunized and susceptible.

A wide overview of CA approaches is provided in books by Codd (2014) and Ilachinski (2001). Ilachhinski describes various approaches to CA and provides many examples of CA applications to physical processes, includingwave propagation and diffusion process.

In our approach, we use ideas of CA combined with the 2D convolution procedure and machine learning method. Specifically, we introduce a regression model in which neighborhood dynamics are included as a feature for model training. In addition, we define states in cells as probabilities (i.e., values between $\mathrm{o}$ and 1 ). Moreover, we modify the uniform influence of deforestation in neighboring cells by introducing spatial distribution (i.e., direction) of impacts by considering stationary features in those cells. This is achieved by the $2 \mathrm{D}$ convolution operation proposed in this study. In that way, we tailor CA for our specific modeling purposes. We did not find this particular formulation of CA in the literature. Further, we find an advantage 
of our approach in that it captures the main features of the model while allowing for acceptable computation time.

\section{Modeling approach}

We introduce a spatially explicit model of the deforestation probabilities evolution, considering the following:

- local drivers of deforestation

- impact of ongoing deforestation in neighboring cells

- cells where deforestation is made impossible

- policy scenarios based on centralized and local thresholds for deforestation

- random deforestation events (e.g., fires).

Our main hypothesis is that deforestation dynamics are driven by relationships between deforested cells and cells that are not deforested. The assumption here is that deforestation is driven by deforestation itself, as this increases access to a particular site. Forested areas in the neighborhood of deforested areas thus have a higher chance of undergoing deforestation as well. In addition, there are local drivers of deforestation that increase its probability depending on the closeness of the area to roads, rivers and socioeconomic and other factors characterizing the area. Therefore, the probability of deforestation is predicated on interactions between two main components: (1) the current and historical status and probabilities of deforestation in the neighborhood; and (2) local drivers of deforestation. Once we assess the probability of deforestation, we can simulate the event of deforestation that is determined by a threshold value in terms of probability. Then, we consider threshold values as policy variables, allowing us to model various scenarios of future development depending on concrete threshold values set for the entire study area or its local subareas. Random deforestation is considered by introducing the Monte Carlo scheme to generate probabilistic thresholds.

In this section, we describe initial datasets, algorithms and model assumptions. The structure of this section is as follows. First, we describe the study area, data and preprocessing. Second, we include the main parameters of the algorithm. Third, we provide details about model training. Finally, we describe assumptions for simulating scenarios. 


\subsection{Study area and time horizon}

We consider the Brazilian state of Mato Grosso, located in the center of Brazil, for our analyses. Figure 1 shows the location of Mato Grosso in Brazil, as well as a detailed state map and its biomes.

\section{FIGURE 1}

\section{Study area: Mato Grosso and its biomes}

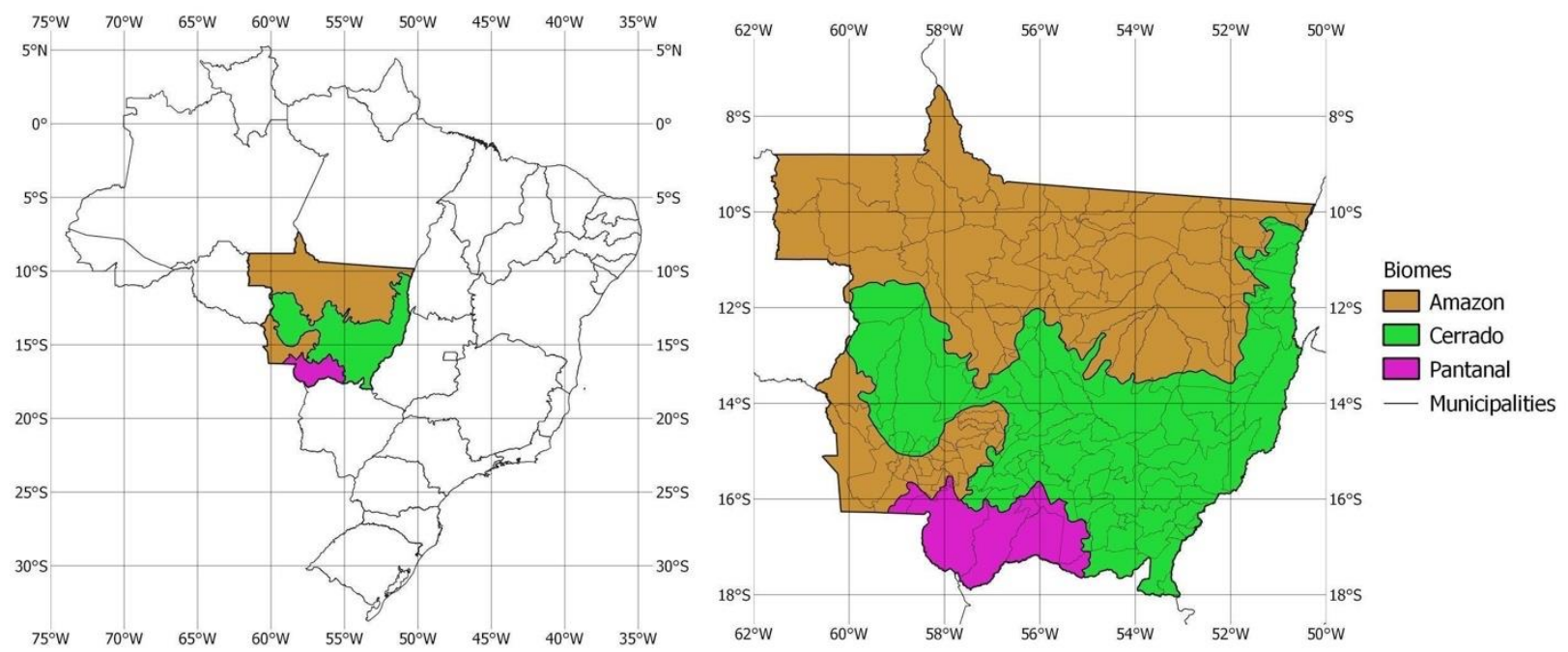

Technically, the area consists of $1,298 \times 1,194$ grid cells, where each grid covers $1 \mathrm{~km}^{2}$. Our sample uses deforestation data from the Secretary of Environment of the state of Mato Gross (SEMA-MT) from 2001 to 2016. These data are used for model training using the approach described below. We use the 2010-19 time period for model warm-up, and the 2020-50 time period for future projections.

Mato Grosso has an area of 90.3 million ha, equivalent to the combines areas of France and Germany. In 2017, 53.5 million ha were covered by native vegetation, spanning three biomes equivalent to approximately $59 \%$ of the state, or an area larger than Spain. Mato Grosso was able to reduce deforestation from 1.278 million ha in 2004 to 0.155 million ha in 2010, a drop of more than $85 \%$ in deforestation over six years across all biomes. It is also an agricultural powerhouse, being the top producer of a handful of agricultural commodities in the country. Yet from 2006 to 2017, the state was responsible for the bulk of deforestation reductions in Brazil, or $40,938 \mathrm{~km}^{2}$ out of $62,321 \mathrm{~km}^{2}$, compared to the 1996-2005 baseline (West et al., 2019). In 
the meantime, both soybean production and head of cattle increased in the state. In addition, Mato Grosso is home to 125,000 smallholder farmers and 43 Indigenous ethnicities spread across 79 indigenous lands (International Policy Centre for Inclusive Growth et al., 2019). For these reasons we chose the state as our area of study, as it is a crucial region for understanding the permanence of deforestation reduction policies in the presence of large agricultural production and Indigenous lands.

\subsection{Data and preprocessing}

In Table 1, we list variables used in our modeling, including their name, description and type. Our outcome variable is yearly deforestation in Mato Grosso. In our model, past deforestation reinforces future deforestation. Other variables control for the spatial patterns of deforestation. First, we account for the state and municipal political boundaries. We then locate each pixel in an ecological zone according to the area's biomes to account for different regulations in the 2012 Brazilian Forest Code. Part of the forest land in Mato Grosso is located in private rural properties, which are mandated to preserve $80 \%$ of their native vegetation in the Amazon (forest), 35\% in the Cerrado (savanna) and 20\% in the Pantanal (wetland). We also include protected areas (i.e., conservation units and Indigenous lands) where deforestation is unlawful. These act as strong, although not perfect, barriers against deforestation. Rural settlements have been identified as hotspots of deforestation (Assunção and Rocha, 2016). 
TABLE 1

Features and variables used in the model

\begin{tabular}{|c|c|c|c|c|}
\hline $\mathbf{N}$ & Feature name & Description & Type & Source \\
\hline 0 & target & $\begin{array}{l}\text { Deforestation for Mato Grosso from } \\
2001 \text { to } 2016 \text { for each year }\end{array}$ & $\begin{array}{l}\text { Binary } \\
\text { (target) }\end{array}$ & $\begin{array}{l}\text { SEMA-MT } \\
\text { (Secretary of } \\
\text { Environment of the } \\
\text { State of Mato Grosso) }\end{array}$ \\
\hline 1 & pasture_yield & Potential yield for grass in $\mathrm{kg} / \mathrm{ha}$ & Numerical & $\begin{array}{l}\text { Food and Agriculture } \\
\text { Organization of the } \\
\text { United Nations/Global } \\
\text { Agro-ecological Zones } \\
\text { (FAO/GAEZ) }\end{array}$ \\
\hline 2 & soy_yield & Potential yield in $\mathrm{kg} / \mathrm{ha}$ & Numerical & FAO/GAEZ \\
\hline 3 & altitude & In meters & Numerical & $\begin{array}{l}\text { Brazilian Ministry of } \\
\text { Environment (MMA) }\end{array}$ \\
\hline 4 & rivers & Distance to rivers in meters & Numerical & $\begin{array}{l}\text { Brazilian National } \\
\text { Water Agency (ANA) }\end{array}$ \\
\hline 5 & rodo10 & Distance to roads in meters & Numerical & $\begin{array}{l}\text { Brazilian Ministry of } \\
\text { Transportation (MT) }\end{array}$ \\
\hline 6 & terrain slope & In degrees & Numerical & $\begin{array}{l}\text { Federal University of } \\
\text { Minas Gerais - } \\
\text { Remote Sensing } \\
\text { Center }\end{array}$ \\
\hline 7 & biomes & $\begin{array}{l}\text { This splits the state into three } \\
\text { biomes: } \\
\text { - Amazon (forest) } \\
\text { - Cerrado (savanna) } \\
\text { - Pantanal (wetland) }\end{array}$ & Categorical & $\begin{array}{l}\text { Brazilian Ministry of } \\
\text { Environment (MMA) }\end{array}$ \\
\hline 8 & islands & Rural settlements & Categorical & $\begin{array}{l}\text { National Institute for } \\
\text { Settlements and } \\
\text { Agrarian Reform } \\
\text { (INCRA) }\end{array}$ \\
\hline 9 & indigenous_lands & Indigenous lands & Categorical & MMA \\
\hline 10 & uc_todas_mt & Conservation units in Mato Grosso & Categorical & MMA \\
\hline 11 & mue & $\begin{array}{l}\text { The municipality boundaries of Mato } \\
\text { Grosso }\end{array}$ & Categorical & $\begin{array}{l}\text { Brazilian Institute of } \\
\text { Geography and } \\
\text { Statistics (IBGE) }\end{array}$ \\
\hline
\end{tabular}

\subsection{Decay of deforestation events}

In the historical data, the target variable - deforestation - is represented by binary variables, indicating the year in which the deforestation occurred. We also assume that once a cell is deforested it stays that way forever. If we kept that assumption, deforested cells would stay at value 1 in all years of simulation runs, which would make it hard to distinguish their influence over time. As our model deals with influence of neighbors and probabilities (values between $o$ 
and 1), we proposed the following transformation of binary values to take into account dynamic effects of deforestation.

Our decay approach reduces historical deforestation impacts based on the idea that deforestation that happened farther back in time has less impact compared to the most recent deforestation events (Fearnside, 1982). Considerthat deforestation in pixel $(i, j), i=1, \ldots, Q, j=$ $1, \ldots, P$, took place $n$ years ago. Here, $Q$ and $P$ are the number of rows and columns, respectively, of a matrix corresponding to the study area map. At current time, $t$, we decay deforestation events in each pixel according to the equation:

$$
d_{i j}(t)=\delta^{n} d_{i j}(t-n), d_{i j} \in[0,1], t \in\left[t_{0}, T\right], n \in\left[0, t-t_{0}\right]
$$

Eq. 1

where $\delta$ is the decay factor. We set the decay factor as $\delta=0.85$. The corresponding matrix of decayed deforestation at time $t$ is denoted by $D(t)=\left(d_{i j}(t)\right) \in \mathbb{R}^{Q \times P}$.

FIGURE 2

Decayed deforestation in relation to the year 2000 , with a decay factor of $\delta=\mathbf{0 . 8 5}$
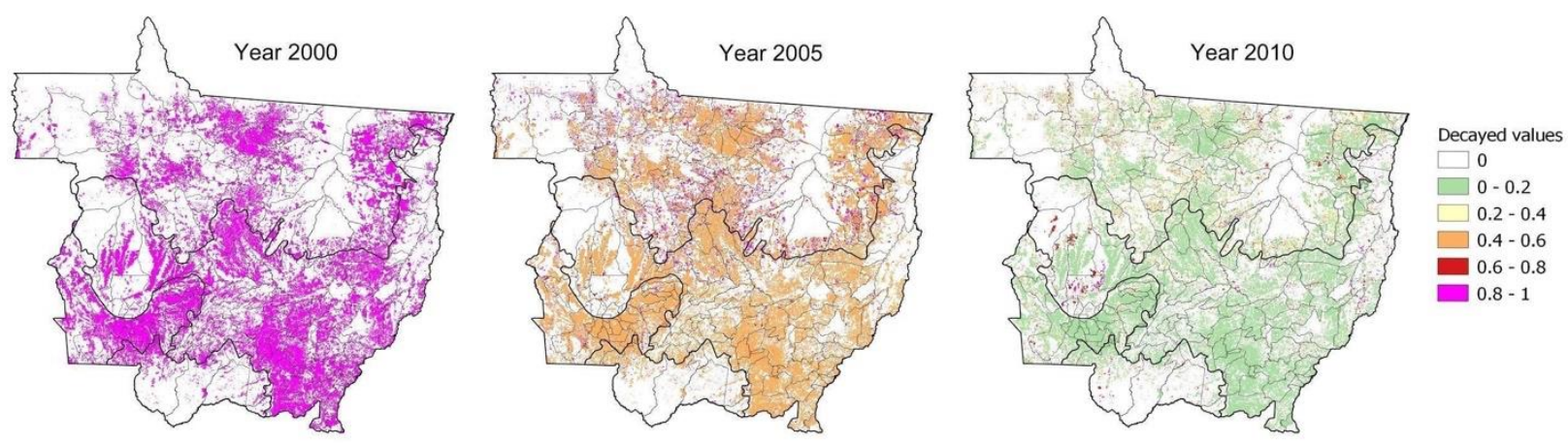

Application of decay to the deforestation data is illustrated in Figure 2. The earliest information about deforestation dates back to 2000, therefore in this year all pixels deforested as of that date have values equal to 1. After five years, those pixels deforested in 2000 decay and their values equal 0.44 (colored orange in the figure) in 2005. At the same time, more recent deforestation events have happened and are happening in 2005, and the values at these locations are higher (red and magenta colors). In 2010, pixels deforested in 2000 decay to 0.197 (colored green) and pixels deforested in 2005 decay to 0.44 (colored orange). 


\subsection{Model training}

For model training, we apply a method based on gradient boosting from machine learning techniques. The scheme of feature collection is shown in Figure 3. We use stationary data from Table 1 and combine it with deforestation dynamics in the neighborhood to predict the target variable. The target is decayed deforestation, as explained in the preceding section, represented by a value between $o$ and 1 . The reason for predicting decayed values is because this is the only target the model "knows." A lower value means that deforestation could potentially happen long ago, while a higher value indicates that deforestation might happen recently. As deforestation has not yet happened, the latter indicates the higher probability that it will. Thus, the "time" is reflected in the model when we predict future deforestation will take place - i.e., the higher the predicted decayed value, the sooner deforestation is likely to happen.

The regression model takes the following form:

$$
\begin{gathered}
d_{i j}(t+1)=\operatorname{MODEL}\left[W_{i j}^{k}, \sum H_{i j}(t), \sum H_{i j}(t-1), \sum W_{i j}^{l}(t), \sum W_{i j}^{l}(t-1)\right], \\
k=1, \ldots, K, l=1, \ldots, L, L \leq K
\end{gathered}
$$

where $d_{i j}(t)$ is decayed deforestation in the cell $(i, j)$ at time $t, d_{i j} \in[0,1]$. Here, $W_{i j}^{k}, k=1, \ldots, K$, are stationary features in cell $(i, j)$; they are components of $K$ matrices $W^{k}=\left(W_{i j}^{k}\right) \in \mathbb{R}^{Q \times P}$. Variables corresponding to stationary features are provided in Table 2, where $K=11$. 
FIGURE 3

Scheme of feature collection

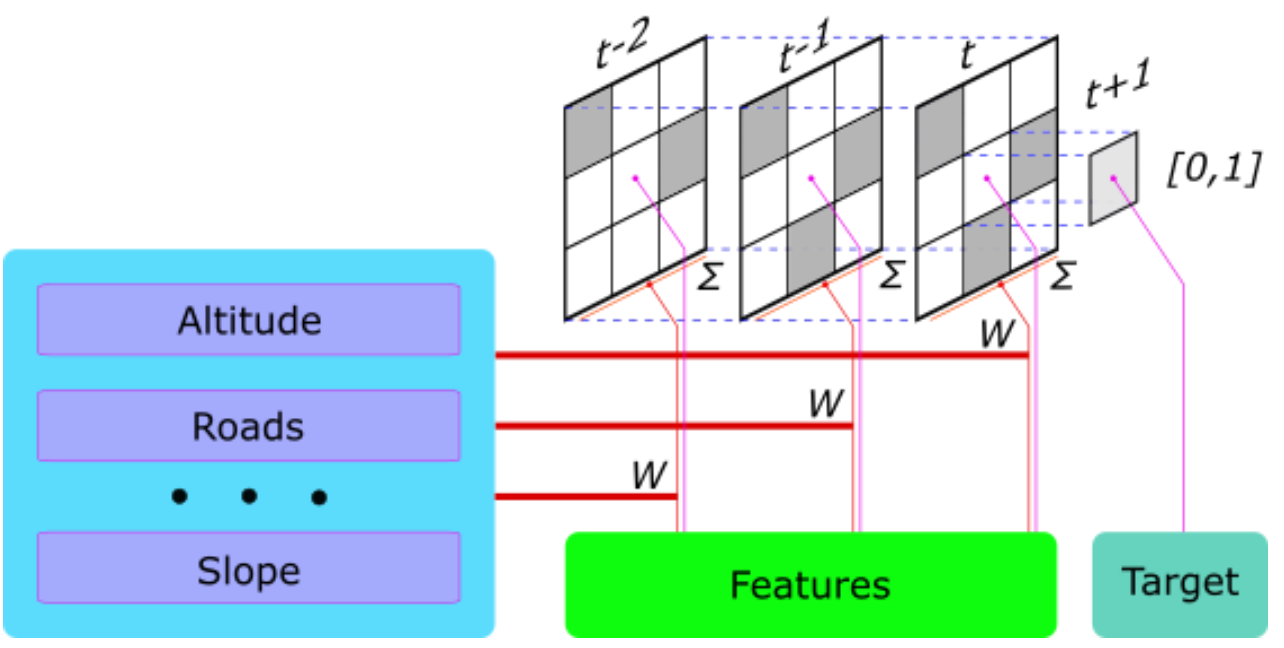

TABLE 2

Stationary features in the regression model (see Eq. 2)

\begin{tabular}{ll} 
Symbol & Name \\
\hline$W^{1}$ & pasture \\
\hline$W^{2}$ & soy \\
\hline$W^{3}$ & altitude \\
\hline$W^{4}$ & rivers \\
\hline$W^{5}$ & rodo10 \\
\hline$W^{6}$ & slope \\
\hline$W^{7}$ & biomes \\
\hline$W^{8}$ & islands \\
\hline$W^{9}$ & indigenous_lands \\
\hline$W^{10}$ & uc_todas_mt \\
\hline$W^{11}$ & mue \\
\hline
\end{tabular}


$\sum H_{i j}(t)$ is the sum of targets in the neighborhood of cell $(i, j)$ at time $t$ and has the form:

$$
\sum H_{i j}(t)=\sum_{r=-1}^{1} \sum_{s=-1}^{1} d_{i+r j+s}(t)
$$

Eq. 3

$\sum W_{i j}^{l}(t), l=1, \ldots, L$, is a convolution of selected features $W_{i j}^{l}$ at cell $(i, j)$ at time $t$, described by the formula:

$$
\sum W_{i j}^{l}(t)=\sum_{r=-1}^{1} \sum_{s=-1}^{1}\left(d_{i+r j+s}(t)-0.5\right) \cdot W_{i+r j+s}^{l} .
$$

Convolution $\sum W_{i j}^{l}(t), l=1, \ldots, L$, determines the direction of deforestation spread and shows interaction between adjacent cells in neighborhood of grid cell $(i, j) . W_{i j}^{l}$ are $L$ selected features from $K \geq L$ stationary features $W_{i j}^{k}$. We considered only numerical features. The sum of neighboring cells in Eq. 3 is symmetrical by default. However, in Eq. 4 we couple it with other features. This helps us make the influence asymmetrical because it is adjusted to additional factors, which in general vary around each cell. Those features complement the actual impact of deforestation as defined in Eq. 3 .

We must note that since $d_{i j}(t)$ can often be zero, we lose information about features in such neighbouring cells during the convolution operation (Eq. 4). To eliminate this, we rescaled it by subtracting 0.5 from $d_{i j}(t)$ (see Eq. 4). As the result, we construct $L$ matrices $\sum W^{l}(t)=$ $\left(\sum W_{i j}^{l}(t)\right) \in \mathbb{R}^{Q \times P}$ containing additional time-dependent features.

Table 3 provides variable names for new features $\sum W^{l}(t), \sum H(t)$, where $L=6$.

In our model, we account for both the current and previous time steps. We consider an iterative process of feature formation. After each iteration $d_{i j}(t+1)=\operatorname{MODEL}[\cdot]$, we obtain matrix $D(t+1)=\left(d_{i j}(t+1)\right) \in \mathbb{R}^{Q \times P}$ of decayed deforestation, which is used for the feature formation: $\sum W^{l}(t+1)=\left(\sum W_{i j}^{l}(t+1)\right) \in \mathbb{R}^{Q \times P}, \sum H(t+1)=\left(\sum H_{i j}(t+1)\right) \in \mathbb{R}^{Q \times P}$. 
TABLE 3

\section{Time-dependent features and their names}

\begin{tabular}{cl} 
Symbol & Name of variable \\
\hline$\sum H(t-g)$ & target_sum_g \\
\hline$\sum W^{1}(t-g)$ & pasture_Wg \\
\hline$\sum W^{2}(t-g)$ & soy_Wg \\
\hline$W^{3}(t-g)$ & altitude_Wg \\
\hline$\sum W^{4}(t-g)$ & rivers_Wg \\
\hline$\sum W^{5}(t-g)$ & rodo10_Wg \\
\hline$\sum W^{6}(t-g)$ & slope_Wg
\end{tabular}

Note: The name of each variable has the form feature_Wg. This means that we apply the convolution operation to matrix $W$ of a feature; $g$ is the number of time steps backwards, $g \in\{0,1\}$. 1, previous step; 0 , current step.

Mato Grosso boundaries are used as spatial constraints, assuming that deforestation beyond the state boundaries is equal to zero. Hence, $d(t)=0$ is fixed for grid cells on the border and outside of Mato Grosso for all $t$.

For model training, we created a dataset with target variable $D(t), t \in\left[t_{0}, T\right]$ and the corresponding variables from Tables 2 and 3. First, we created a dataset for the entire area and all time steps. This dataset contains all features used in the model (see Eq. 2). Second, we split this dataset randomly into the train and test sets in the proportion of $70 \%$ to $30 \%$. We solved the regression problem in Eq. 2 using the LGBMRegressor method from the LightGBM gradient boosting framework (Ke et al., 2017). For tuning model parameters, we used the train set. We applied K-fold cross validation with five folds and a randomized search of parameters through the grid of fixed range. To assess model quality, we considered coefficient of determination $\mathrm{R}^{2}$. This represents the proportion of variance of decay deforestation that is explained by 
independent variables in the model. After validation on the test set, we obtained an $\mathrm{R}^{2}$ score of 0.455. The features, sorted by their importance in the model, are given in Table 4. The most important features are those dealing with neighboring cells. Therefore, this outcome confirms our hypothesis about deforestation drivers.

TABLE 4

The importance of features used in the model

\begin{tabular}{|c|c|c|}
\hline $\mathbf{N}$ & Feature & Importance of feature \\
\hline 1 & target_sum_0 & 0.167 \\
\hline 2 & target_sum_1 & 0.081 \\
\hline 3 & soy_W0 & 0.059 \\
\hline 4 & soy & 0.053 \\
\hline 5 & islands & 0.047 \\
\hline 6 & altitude & 0.046 \\
\hline 7 & pasture_W1 & 0.046 \\
\hline 8 & mue & 0.044 \\
\hline 9 & soy_W1 & 0.039 \\
\hline 10 & rodo10 & 0.038 \\
\hline 11 & pasture_W0 & 0.035 \\
\hline 12 & altitude_W1 & 0.032 \\
\hline 13 & slope_W0 & 0.031 \\
\hline 14 & rivers_W1 & 0.030 \\
\hline 15 & altitude_W0 & 0.030 \\
\hline 16 & rivers_W0 & 0.029 \\
\hline 17 & biomes & 0.027 \\
\hline 18 & pasture & 0.027 \\
\hline 19 & rodo10_W1 & 0.026 \\
\hline 20 & rodo10_W0 & 0.026 \\
\hline 21 & slope_W1 & 0.025 \\
\hline 22 & rivers & 0.019 \\
\hline
\end{tabular}




\begin{tabular}{lll}
\hline 23 & indigenous_lands & 0.018 \\
\hline 24 & slope & 0.015 \\
\hline 25 & uc_todas_mt & 0.008 \\
\hline
\end{tabular}

Note: See Tables 2 and 3 for notations.

A predictable initial reaction to some of the relatively small $\mathrm{R}^{2}$ scores is that perhaps the correlation is not as expansive as we might have predicted. However, taking into account the presence of random deforestation in the historical data that is explained neither by internal factors nor interaction with neighboring cells provides helpful context. The appearance of a correlation, however slight, indicates that there is a relationship between the two variables that is statistically significant despite the preponderance of seemingly random deforestation. In the simulation portion of this paper, we propose a Monte Carlo approach to allow such random deforestation events to be taken into account.

During model training we did not force barriers (e.g., Indigenous lands and conservation units) to be unavailable for deforestation. However, based on the historical data the model learned to consider those areas as having very low probability for deforestation.

\subsection{Simulation of scenarios}

The trained model allows assessment of the spatial dynamics of deforestation probabilities. After passing to decays, we predict probabilities as target variables, represented by values from o to 1 , in the cells where no deforestation has previously occurred. We call these "probabilities of deforestation.”

In order to identify an event of deforestation, we set a threshold value N. As soon as this threshold is reached, the pixel is marked as 1 and is considered to be deforested, and the decay factor is applied in all next steps from probability equal to 1 at the year of deforestation. Once a pixel is deforested, we don't apply any other operations except decaying. Thresholds are applied to deforestation probabilities only in pixels marked as o, i.e. standing forest land. Therefore, we track two maps in parallel:

- a map of probabilities, including both deforested and forested pixels

- a map of o's and 1's (e.g., the status of each pixel).

We use the second type of maps for model output and the first type for modeling. 
In modeling thresholds, we apply both deterministic and probabilistic approaches. In a deterministic case, we deal with prescribed deforestation thresholds. In a probabilistic approach, we use Monte Carlo to identify deforestation events at each step. For this purpose, we add random deforestation by the following rule: $\tilde{u}=a \cdot u^{b}$, where $u \in \operatorname{Uniform}(0,1)$, where $a, b$ are parameters. We set $a=1$ and $b=0.5$.

Considering probabilistic and deterministic thresholds, a current threshold is defined by formula: $N_{f}=\min \{\mathrm{N}, \tilde{u}\}$, where $\mathrm{N}$ is the prescribed threshold. Therefore, the deforestation takes place either when a fixed threshold $\mathrm{N}$ is reached or there is a random event that indicates it could happen at the lower threshold $\tilde{u}$.

For this reason, we chose a random threshold from a transformation of a uniform distribution, as illustrated in Figure 4. This helps to reduce the chances of obtaining very low values for probabilistic thresholds that would mean an immediate deforestation in many grid cells. For example, if the random generator gives the value $u=0.2$ it is transformed to $\tilde{u}=0.447$.

FIGURE 4

Transformation of random threshold $u$ from uniform distribution test into threshold $\widetilde{u}$

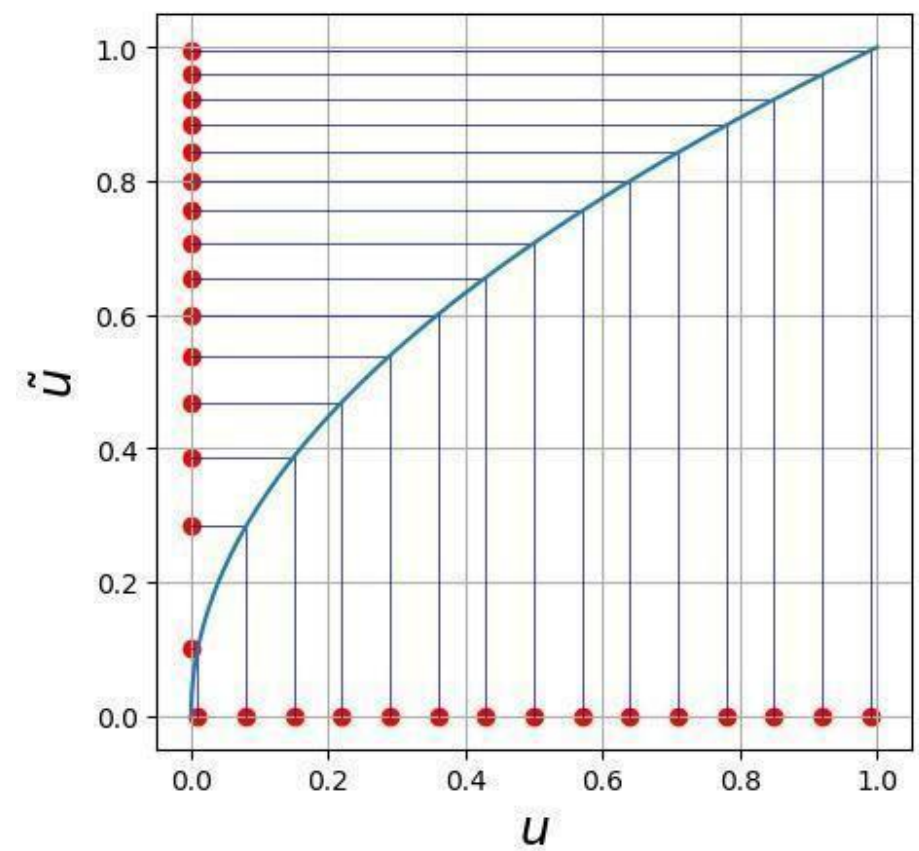

The simulation runs through 2050. We used the interval 2010-19 for model initialization, and then, from 2020 onwards, we introduced thresholds. During the initialization interval, only 
probabilistic thresholds are implemented. Initialization is necessary for the model to reach a stable mode of operation. During this interval, the nearest-neighbor mechanism manifests itself sharply and some time is needed for saturation of this mechanism to normal mode. This happens because we do not have any fixed time interval during the training period, as we take arbitrary subsets of data for learning and testing, which differs from the time-series approach. Figure 5 shows how the threshold part of our model works. For illustration, we set a deterministic threshold to $\mathrm{N}=1$, meaning that deforestation never happens. Therefore, the only active threshold is probabilistic - i.e., a random test can set a value below 1 in some cells, thus potentially leading to deforestation due to accidental exogenous factors, such as fire. One can see that deforestation rates are declining in this case, but are still positive. Five simulations are shown in this figure in addition to the average values. It can be seen that randomization is reasonable and does not produce any explosive effects - i.e., the spread of stochastic runs around the mean is bounded. In all simulations deforestation falls from about $1,500 \mathrm{~km}^{2}$ per year to about $700 \mathrm{~km}^{2}$ per year. 
FIGURE 5

\section{Deforestation scenario with threshold $\mathrm{N}=1$}

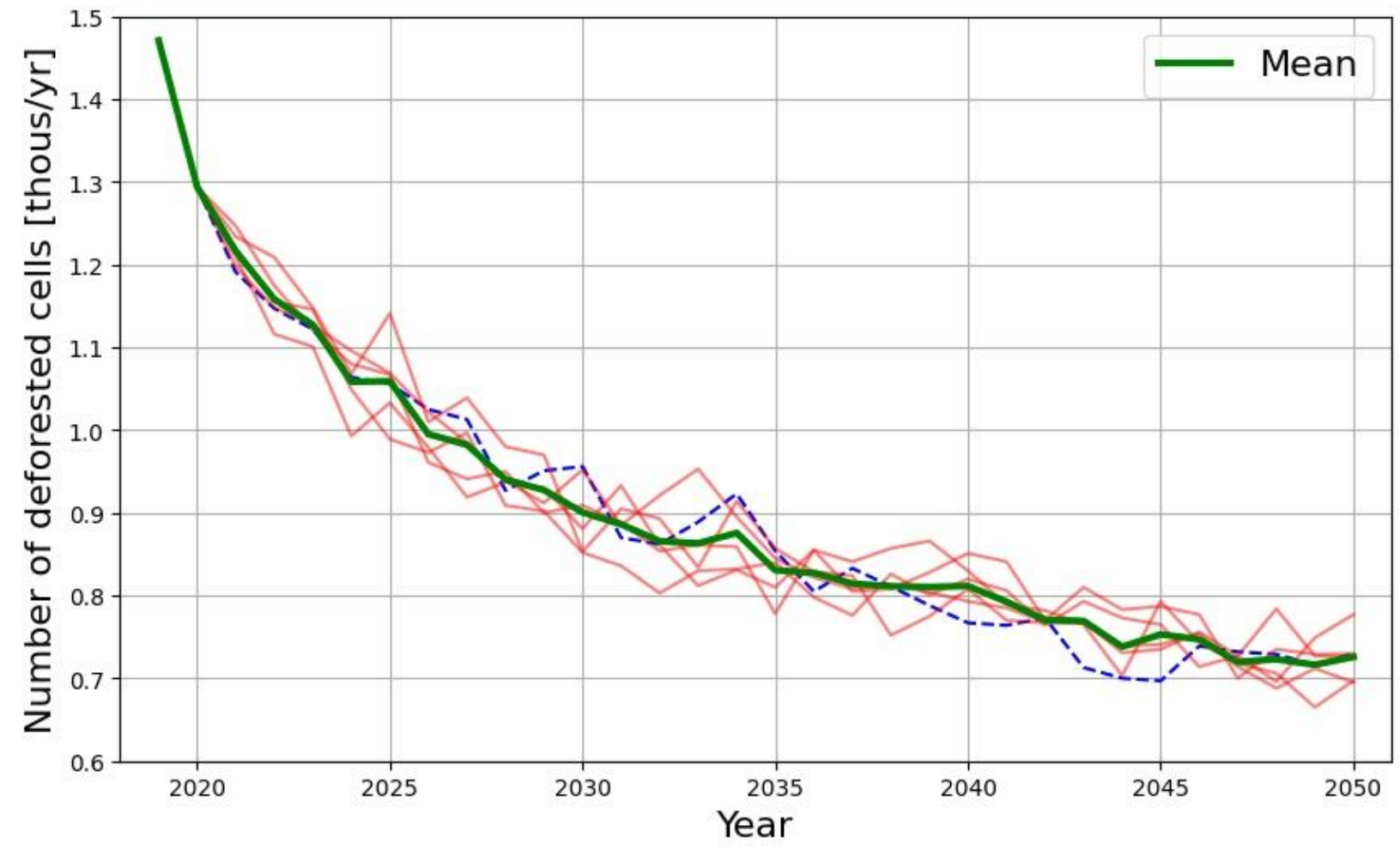

Note: Deforestation rates are the number of deforested cells per year. The green line represents the mean of stochastic simulations. The dashed blue line represents a stochastic simulation used in the Results section. Other lines are representative of individual model runs. The spread of stochastic runs around the mean is bounded

A more realistic situation is when the threshold is set to $\mathrm{N}=0.35$ for the entire area. The dynamics of deforestation rates in this case are shown in Figure 6. We consider this scenario as a baseline for our future runs. One can see that in terms of deforestation rates the model shows U-shaped behavior. At first, the number of deforested cells grows at an increasing rate until the growth rate reaches its maximum. After its peak, growth starts to saturate. This behavior would result in the S-shaped curves in cumulative values shown in Figure 8. We also present several Monte Carlo runs, showing that deviation from the mean is less than $10 \%$. The concave shape in Figure 6 is explained by the decreasing number of cells available for deforestation, because we do not model any afforestation in this study. This pattern of deforestation dynamics is found in other studies. The falling rate of deforestation during the period 2035-50 illustrates a rather catastrophic situation: at this stage the number of deforested cells is so high that the spread slows down because of this. 
FIGURE 6

\section{Deforestation scenario with threshold $\mathrm{N}=0.35$}

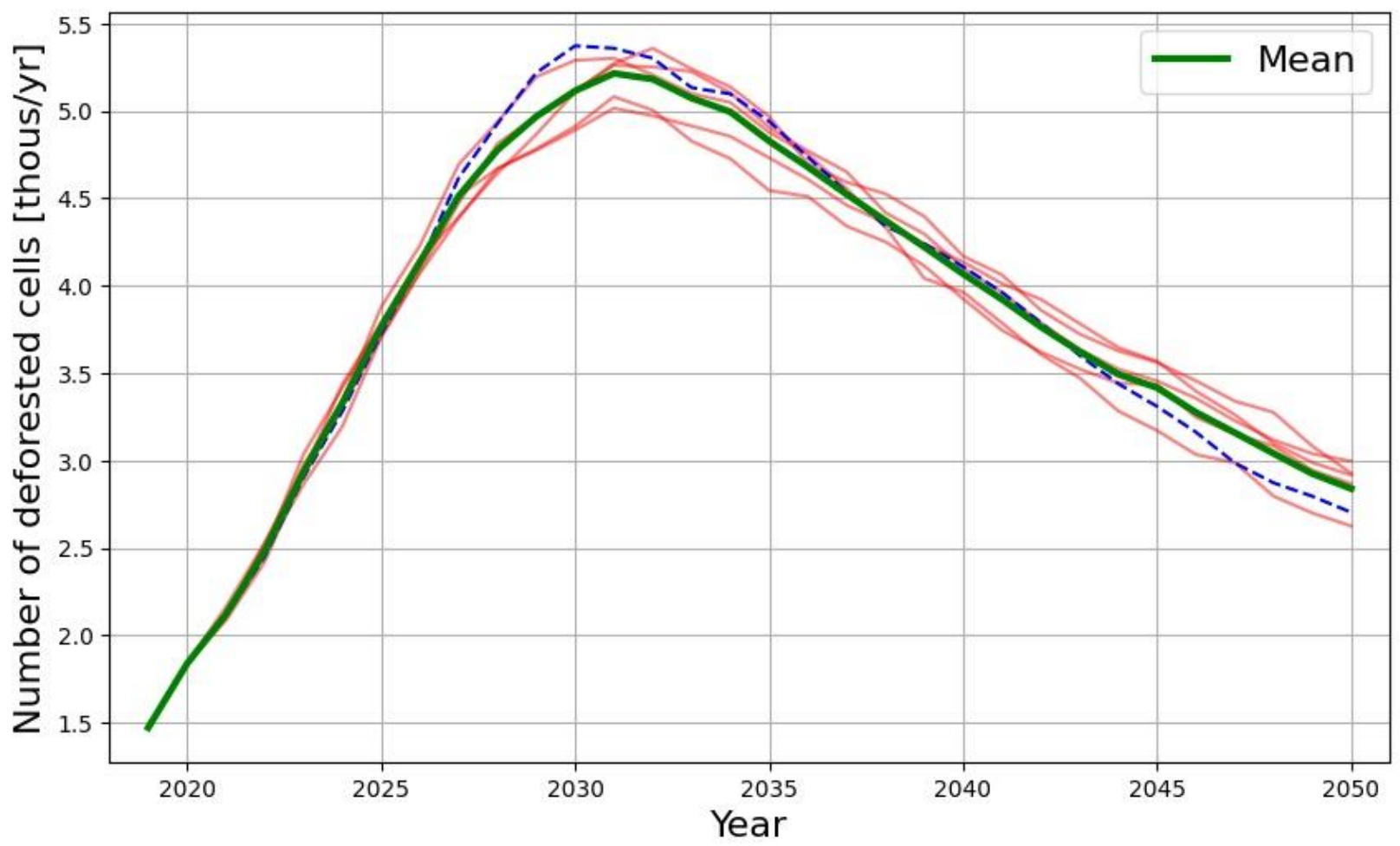

Note: Deforestation rates are th number of deforested cells per year. The green line represents the mean of stochastic simulations. The dashed blue line represents a stochastic simulation used in the Results section. Other lines are representative of individual model runs. The spread of stochastic runs around the mean is bounded.

\section{Results}

In this section we present results of our simulated policy intervention at the jurisdictional scale.

First, we modeled a jurisdictional command-and-control policy affecting the state of Mato Grosso. We simulate a tightening of law enforcement to curb deforestation during the period 2025-34 by increasing the threshold at which cells are deforested compared to BAU, implemented by shifting from $\mathrm{N}=0.35$ to $\mathrm{N}=0.4$.

Next, in order to understand the permanence of avoided deforestation and related carbon emissions for this command-and-control policy intervention, we modeled four different scenarios. First, the tighter law enforcement policy $(\mathrm{N}=0.4)$ is maintained throughout 2050. 
We modelled three alternative levels of loosening law enforcement by decreasing the threshold of deforestation for all cells across the jurisdiction to $\mathrm{N}=0.38, \mathrm{~N}=0.35$ (BAU value) and $\mathrm{N}=$ 0.33. This captures the possibility of a policy rollback triggered in 2035 .

Our simulations allow us to understand the intertemporal effects of such a command-andcontrol policy and analyze changes in deforestation and emissions patterns in the absence or presence of future policy reversals.

\subsection{Centralized scenarios with variable thresholds}

In this subsection we consider scenarios applied to all the cells, i.e. centralized policies.

FIGURE 7

\section{Deforestation scenarios under centralized policies}

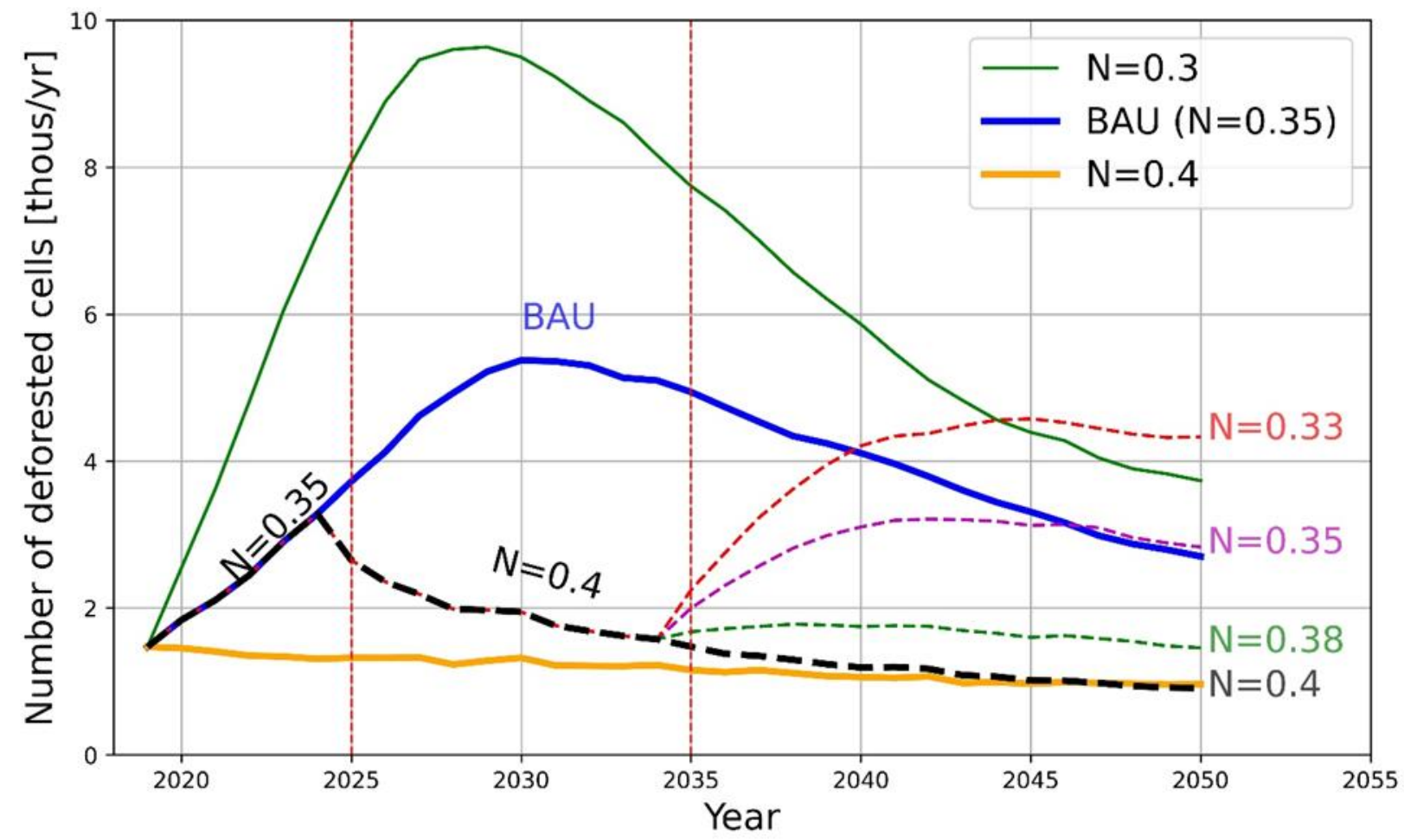

Figure 7 shows the dynamics of deforested cells in each year during the period 2020-50. The orange, blue and green lines show the dynamics for thresholds 0.4, 0.35 and 0.3, correspondingly. Our simulations show that the range for thresholds is between 0.3 and $0.4-$ i.e., the model is quite sensitive to the changes in thresholds. This is connected with other 
parameters of the model as well as the chosen decay rates and timescale. We set threshold 0.35 as a baseline threshold; 0.4 corresponds to tighter law enforcement and low deforestation pressure, and threshold 0.3 is a rather extreme scenario of loose law enforcement and deforestation boom.

In the first scenario we introduce a policy intervention from 2025 to 2034 to slow down the BAU deforestation by increasing the threshold to 0.4. One can see the positive effect of this policy in Figure 7: the blue trajectory is switched to the black dashed line. If this policy were to be kept, deforestation would decline until 2050. However, if from 2035 to 2050 we change the threshold value of 0.4 to lower values, we see that deforestation rises again depending on the chosen threshold. Although the period of tight deforestation control has its positive effects, deforestation rates reach the BAU levels at 2050 (magenta dashed line) or can go even higher (red dashed line) if the threshold is lower than the BAU threshold. The purpose of experimentation with different thresholds is to detect a critical level after which avoided deforestation could be treated as permanent.

FIGURE 8

\section{Cumulative number of deforested cells}

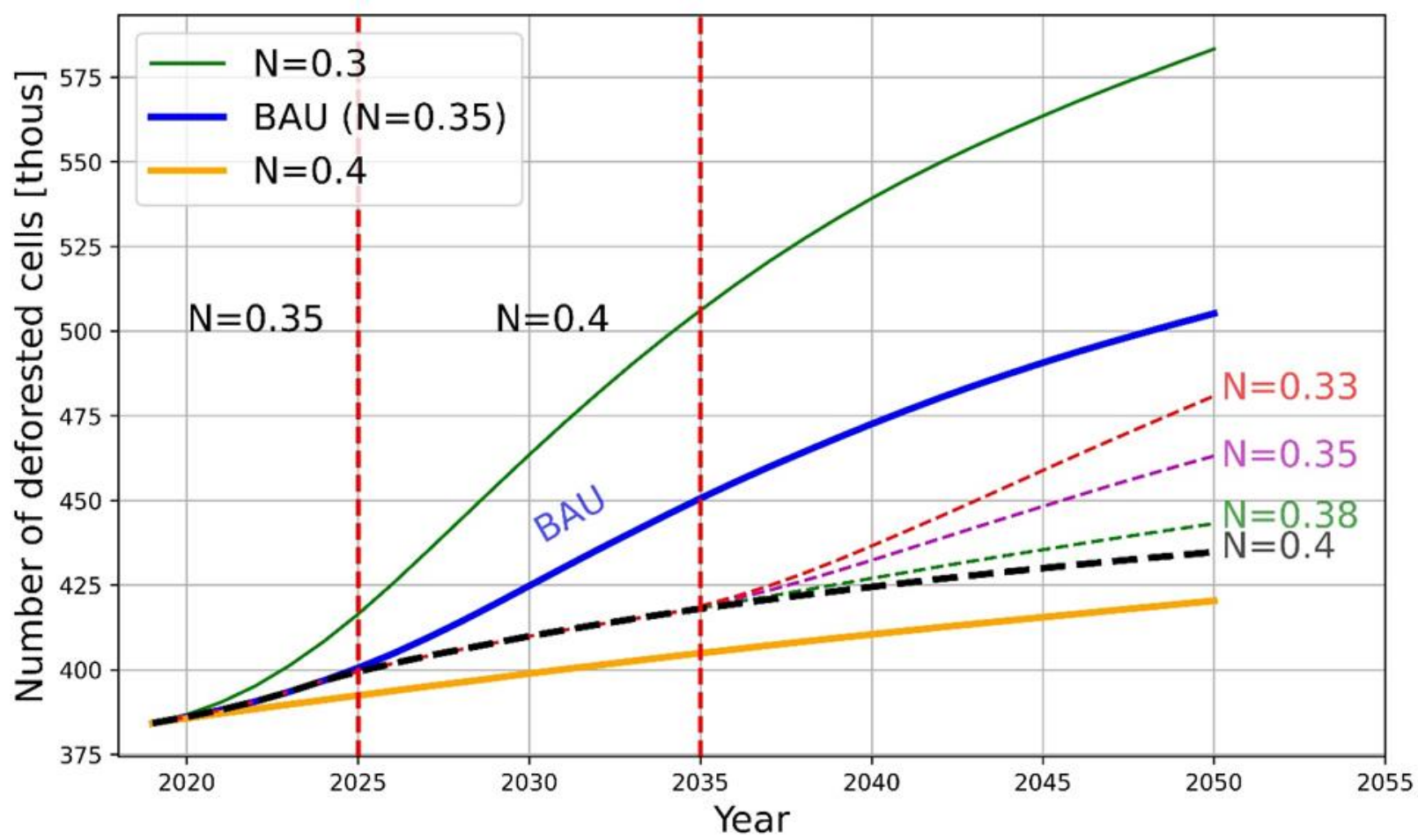


Figure 8 illustrates the cumulative deforestation values corresponding to the annual deforestation in Figure 7. Here, we observe that temporary deforestation control (2025-34) has positive permanent effects even if the policy is temporary: in cumulative values all the dashed curves are below the BAU curve by 2050.

Nevertheless, because of the high deforestation rates at threshold $\mathrm{N}=0.33$ following the end of deforestation control in 2034 shown in Figure 7, there is a possible negative outlook after 2050 in that scenario. The model exhibits permanent effects for $\mathrm{N}=0.4$ and higher.

\subsection{Spatial dynamics and barriers}

The illustration of spatial dynamics of deforestation corresponding to the BAU scenario (Figure 7) is shown in Figure 9 for years 2035 and 2050. We see that in 2035 the deforestation process is still in an active stage. The hotspots are shown in magenta and red colors. The spreading process is well illustrated in particular by comparing two spreading areas in 2035 and 2050 in the panhandle at the top of the maps. We also show by hatched shading the Indigenous lands where the probability of deforestation is low. However, we see that deforestation is active at the boundaries of those lands and, in particular, that it will be concentrated in 2050, because it is basically the only direction for deforestation left by that time. We also see that there are some deforested pixels inside those areas, mostly due to the random events simulated in the model. However, they are not spreading due to their location. Although we do not force probabilities to be zero, the model learned to keep them very low in those lands, thus making these areas barriers. 
FIGURE 9

Spatial dynamics of deforestation under the BAU scenario for 2035 and 2050, with Indigenous lands acting as barriers for deforestation
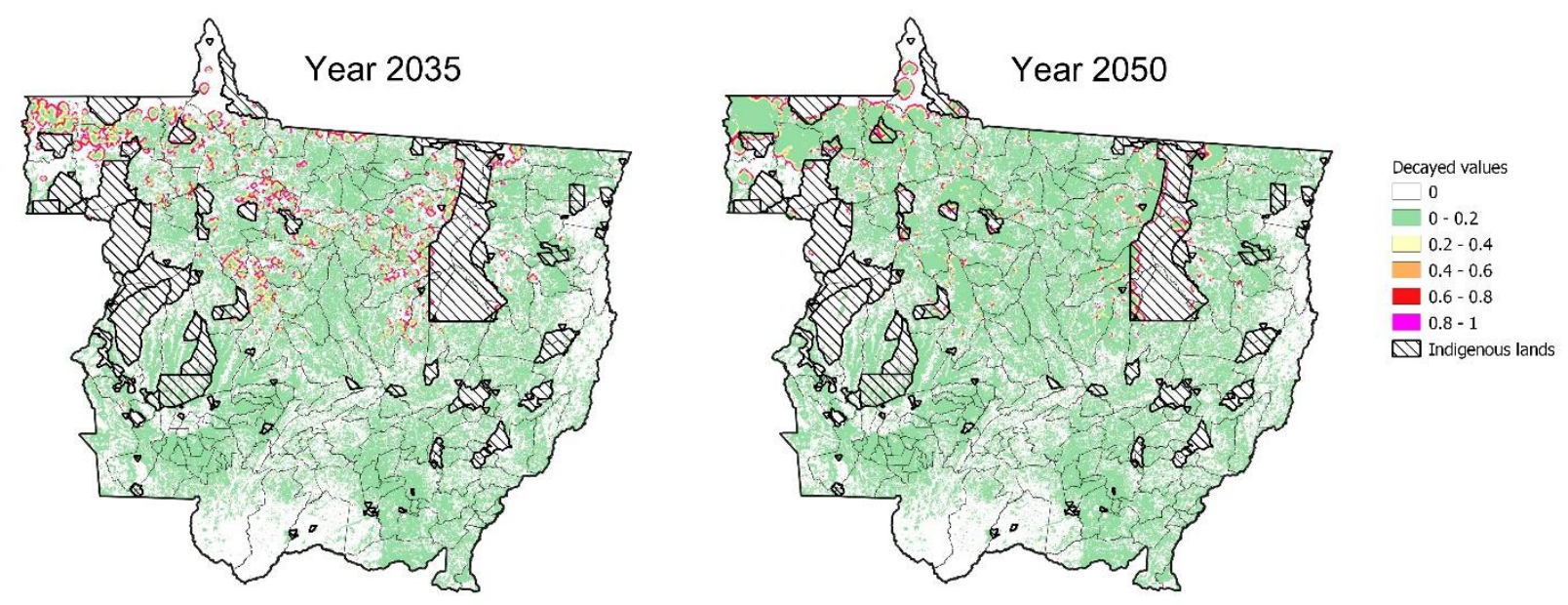

\subsection{Jurisdictional policy impacts}

Here we consider how jurisdictional policies would impact deforestation dynamics in the region according to our model following the legal native vegetation preservation requirements from the 2012 Brazilian Forest Code. We use the following maps as a basis for modeling scenarios: a map containing pixels of $1 \mathrm{~km}^{2}$ size with native vegetation surplus, and a map representing pixels with native vegetation deficit. Both maps are shown in Figure 10. These maps are based on data from Instituto de Pesquisa Ambiental da Amazônia (2021). The total area of surplus is 7.21 million ha while the total area of deficit is 8.76 million ha. 
FIGURE 10

Maps with a native vegetation surplus (left) and deficit (right) used in the study
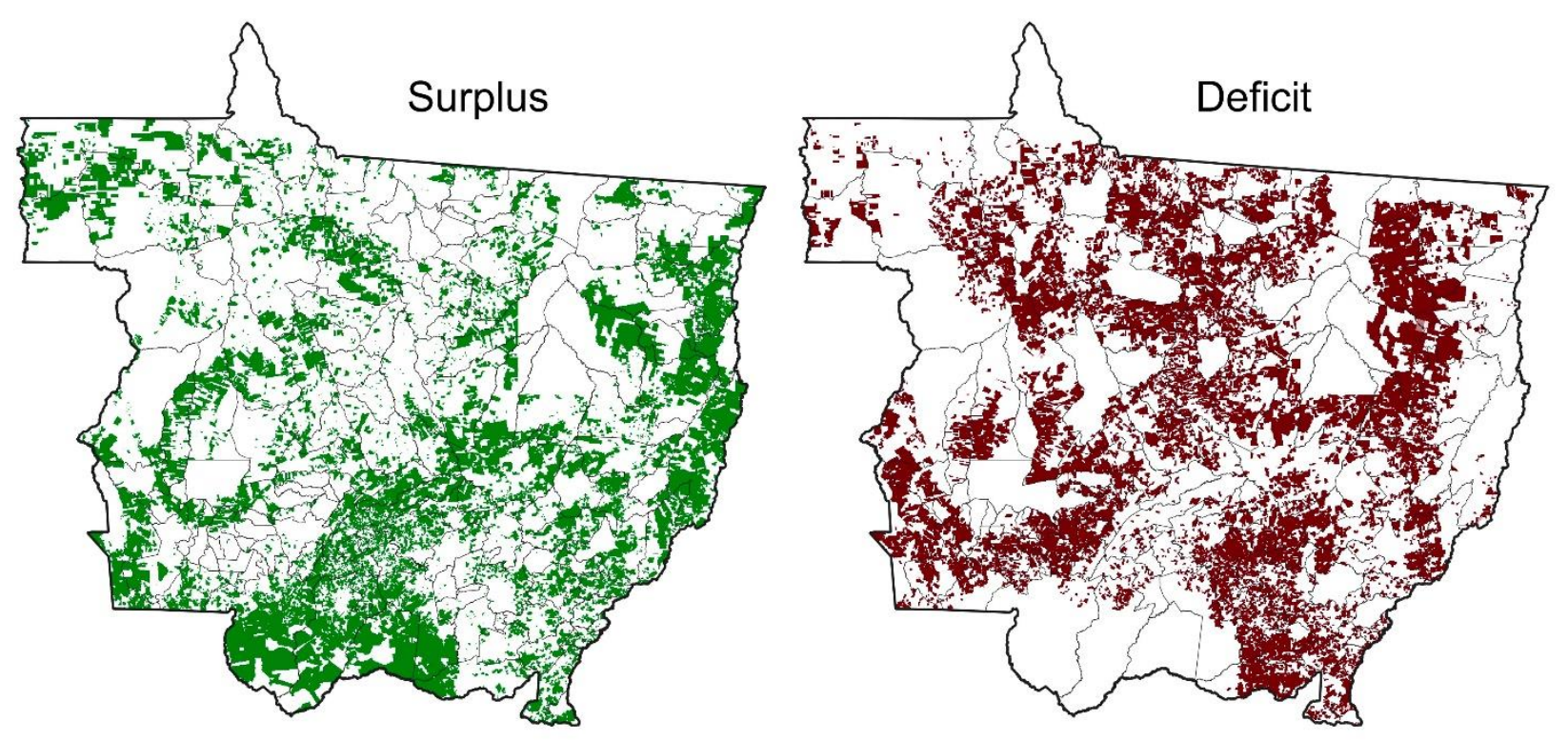

We use such maps to simulate two policies concurrently. The first policy simulates an incentivebased jurisdictional program where payments would be made to landowners with native vegetation surplus, thus blocking those parcels from deforestation. The second policy simulates a command-and-control approach to bring properties back to compliance with the Brazilian Forest Code by reforesting their deficits.

First, deforestation was blocked in all areas with a forest deficit from 2010 until 2050. We considered all those pixels as reforested and protected during the entire time interval. At the same time we considered the following cases for areas with surplus, which were considered reforested in 2010:

- Case 1 - block deforestation from 2010 until 2050

- Case 2 - block deforestation from 2010 until 2030, and allow deforestation afterwards

- Case 3 - block deforestation from 2010 until 2030, allow deforestation in the period 203034, and allow block deforestation afterwards

- Case 4 - block deforestation from 2010 until 2030, allow deforestation in the period 203039, and allow block deforestation afterwards. 
Modeling results are presented in Figure 11, where annual numbers of newly deforested pixels are shown for various scenarios. The difference between BAU and jurisdiction policy cases in 2020 is explained by the fact that areas with deficit and surplus were removed at the start of simulations in 2010. The difference between policy scenarios begins in 2030. The most positive effect is achieved in Case 1, where all selected areas are protected by policy until 2050. In that case the rate of deforestation in the study area is consistently low. In Case 2, when policies are relaxed in surplus areas until 2050 we see a relatively fast increase of deforestation rates with a qualitative behavior similar to BAU scenario; the maximum deforestation rate happens around 2042. Quite interesting effects are observed when the relaxation of policy in 2030 is reversed in 2035 (Case 3) and 2040 (Case 4). The return to protected areas allows to slow down deforestation rates and gradually converge them to the level of Case 1 by 2050. This shows that due to the high number of pixels where policies are applied, the neighboring effect is one of the key factors for spreading deforestation. 
FIGURE 11

Jurisdictional policy impacts compared to BAU scenario (as in Figure 7)

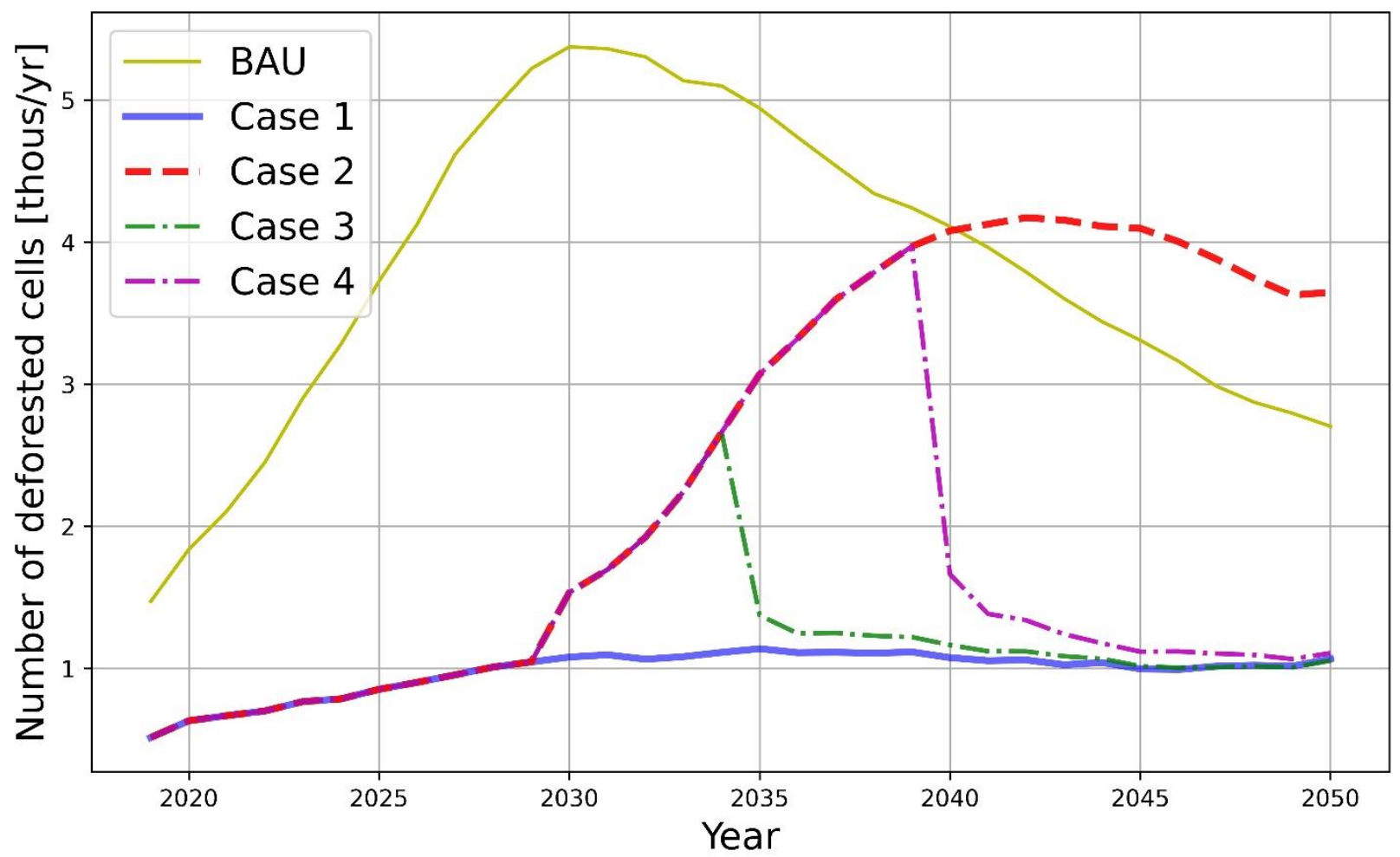

Note: Cumulative deforested areas corresponding to policy scenarios are given in Figure 12. The figure clearly illustrates the impact of policy reversals - i.e., Cases 3 and 4 allow deforestation to be reduced to the levels close to Case 1 . This has some analogy with epidemic models, where policies could be considered as quarantine measures that can be forced and relaxed by governments at various time periods. 
FIGURE 12

Cumulative number of deforested cells in jurisdictional policy scenarios

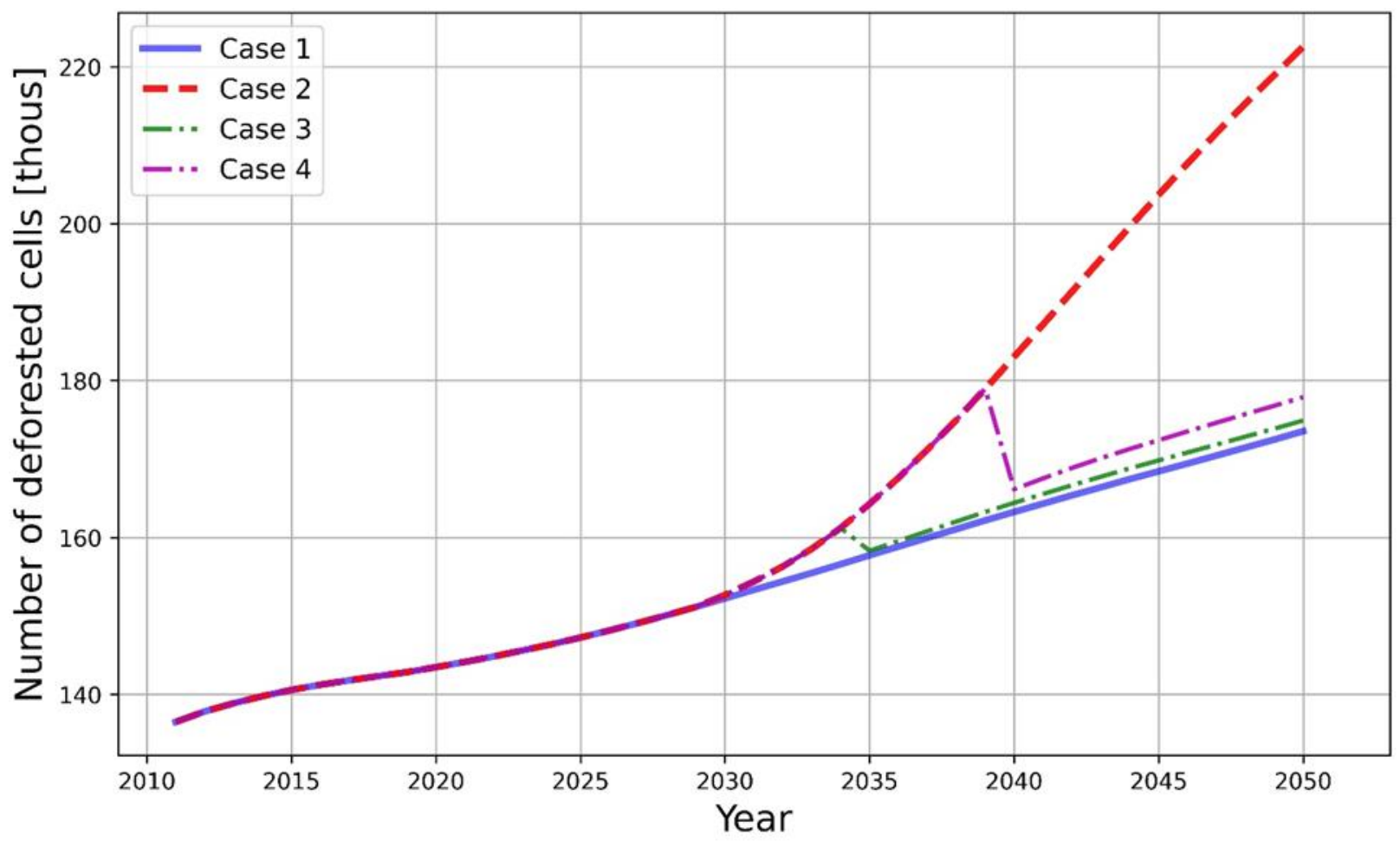

Finally, in Figure 13 we present maps that compare results of the BAU scenario and the Case 1 scenario of jurisdictional policy for 2050. We see that due to the dynamics of neighboring pixels that are in the core of the model, the difference in deforested cells is considerable. This is a positive signal for policy options. 


\section{Comparison of the BAU scenario (left) and Case 1 scenario for 2050 (right)}
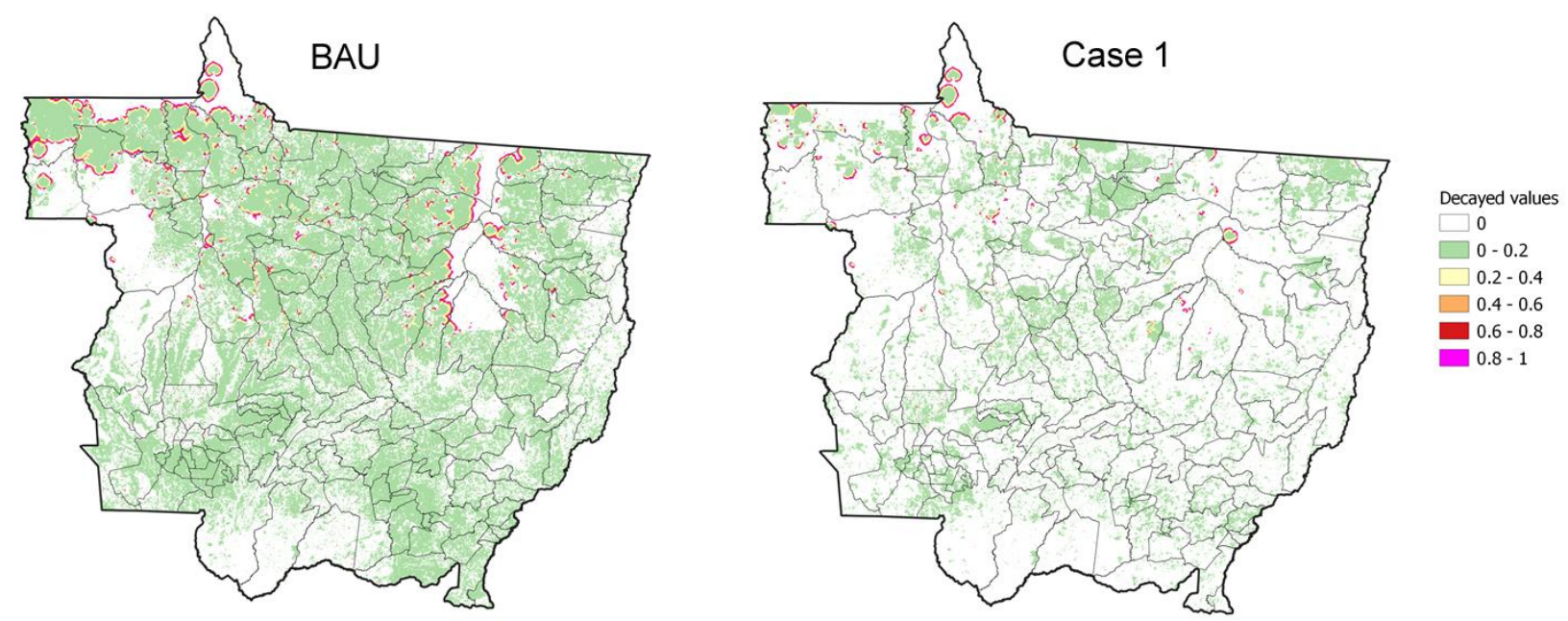

\section{Discussions and conclusions}

In this section we analyze the permanence of avoided emissions by applying a probabilistic model of endogenous deforestation. The CA modeling algorithm considers positive feedback of deforestation of a neighboring land area as well as a threshold effect. Our results suggest a strong path dependence and partial irreversibility of changes in a deforestation pathway. In other words, once it deviates from the BAU trajectory, a deforestation pathway is unlikely to rebound back to BAU. The longer the initial intervention, the less likely the deforestation pathway rebounds. Over time, the economy - previously dependent on deforestation converges to a new steady state not associated with deforestation. The more extended the period of active intervention, the better the chance a tropical nation (jurisdiction) will rebalance natural and manmade capital to support alternative development pathways that do not require deforestation. Additionally, a higher threshold value implies a lower probability that deforestation will rebound back to BAU. This observation leads to an important policy conclusion: prolonged intervention yields better results.

The permanence of a policy depends on its success to reduce cumulative deforestation and emissions compared to the BAU trajectory, and the probability that policy rollbacks and the resulting trajectory of deforestation and emissions do not overshoot the BAU trajectory and outpace previously accumulated deforestation or emissions reductions in the long run. Hence, 
permanence depends both on the probability of policy reversals and their potential overshooting, and the relevant time horizon to be considered (e.g., 2050, 2100, etc.).

Given limited initial resources to support avoided deforestation, we began this study by looking for strategic positioning of the restricted area (subjurisdictional programs and large projects). Deforestation spreads from outside the box. It seems that several boxes are needed to create a stronger effect. The logical next step for this analysis is the application of optimization in the organization of protected areas to study the dynamics of clusters of avoided deforestation. Further, experiments with embedded optimization may answer the questions: If we can spatialize interventions, do they affect deforestation in an outsized fashion? If we reduce deforestation in certain parcels of land, do they affect deforestation distribution in different ways?

\section{Future research}

Future research will address the impacts of market-based policies, namely REDD+ payment programs, on curbing deforestation and permanence of avoided emissions. In our future work, we will analyze the effects of a REDD+ payment program by applying different deforestation restrictions to the model - i.e., size and location constraints to protect certain areas, reflected by boxed areas in the model.

Figures 14 and 15 illustrate how we propose to set up these modeled boxes to investigate the impacts of box location and size on deforestation and permanence. For example, a future scenario might consider making it very difficult to deforest cells within a certain box by setting $N=1$ for those cells, while deforestation of cells outside the box would follow the BAU threshold $(N=0.35)$.

Moreover, we plan to investigate the results of increasing a REDD+ program from project level (small box) to jurisdictional level (the whole state). This will contribute to another heated debate on project versus jurisdictional approaches regarding reducing deforestation. 
FIGURE 14

Proposed scenarios with different box locations (shape $200 \times 200$ )

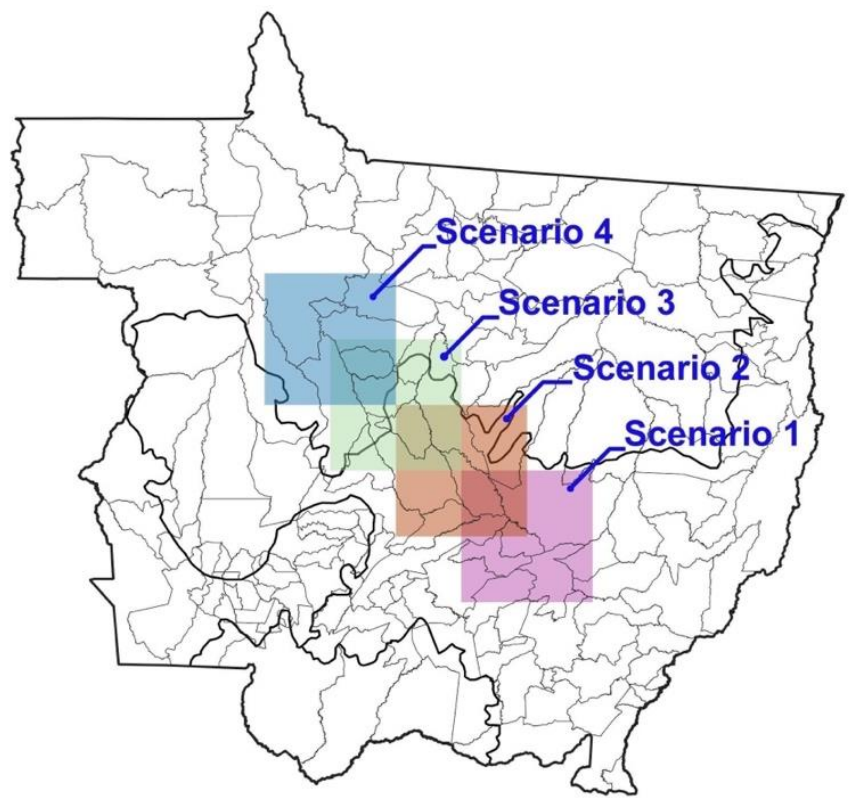

FIGURE 15

Proposed scenarios with different box sizes: Scenario $5(100 \times 100)$,

Scenario 4 (200 $\times 200)$, Scenario $6(300 \times 300)$, Scenario $7(400 \times 400)$

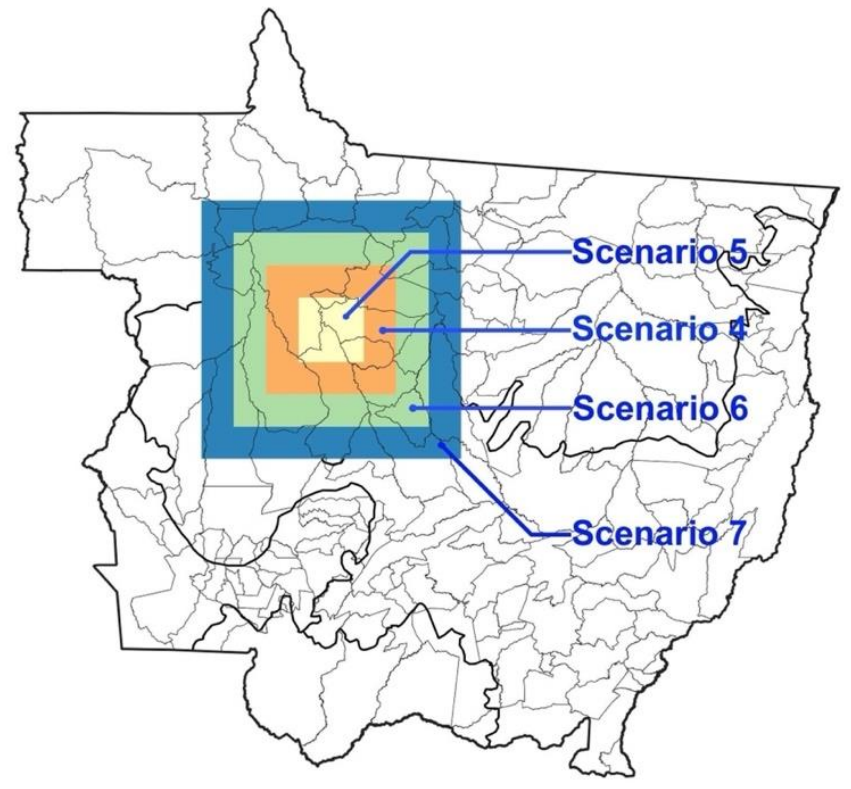


Another direction for further research is to check for spatial synergies among different small boxes. A REDD+ payment program targeted at rural properties may be scattered across the jurisdiction, where each property could be treated as a separate small box. Yet, using an optimization algorithm we may be able to compare alternative results of conducting localized REDD+ payment interventions versus optimizing deforestation reductions over the landscape, given the same budget. This analysis would help to establish a strategy for scaling up jurisdictional REDD+ programs by maximizing environmental benefits at the minimum cost. 


\section{References}

Acheampong, E. O., Macgregor, C. J., Sloan, S. and Sayer, J. (2019). Deforestation is driven by agricultural expansion in Ghana's forest reserves. Scientific African, 5, eo0146. https://doi.org/10.1016/j.sciaf.2019.eo0146

Asner, G. (2006). Measuring carbon emissions from tropical deforestation: an overview. Environmental Defense Fund. https://www.edf.org/sites/default/files/10333 Measuring Carbon Emissions from Tropical Deforestation-An Overview.pdf

Assunção, J. and Rocha, R. (2016). Rural settlements and deforestation in the Amazon (Climate Policy Initiative Working Paper). Climate Policy Initiative. https://www.climatepolicyinitiative.org/publication/ruralsettlements-deforestation-amazon

Barbier, E. B. (2004). Explaining agricultural land expansion and deforestation in developing countries. American Journal of Agricultural Economics, 86(5), 1347-53. https://doi.org/10.1111/j.0002-9092.2004.00688.x

Bowles, I. A., Rice, R. E., Mittermeier, R. A. and da Fonseca, G. A. (1998). Logging and tropical forest conservation. Science, 280(5371), 1899-1900. https://doi.org/10.1126/science.280.5371.1899

Chen, G., Powers, R. P., de Carvalho, L. M. and Mora, B. (2015). Spatiotemporal patterns of tropical deforestation and forest degradation in response to the operation of the Tucuruí hydroelectric dam in the Amazon basin. Applied Geography, 63, 1-8. https://doi.org/10.1016/j.apgeog.2015.06.001

Codd, E. F. (2014). Cellular automata. Academic Press.

Fearnside, P. M. (1982). Deforestation in the Brazilian Amazon: How fast is it occurring? Interciencia, 7(2): 82-85.

Fuss, S., Golub, A. and Lubowski, R. (2021). The economic value of tropical forests in meeting global climate stabilization goals. Global Sustainability, 4(e1), 1-11, https://doi.org/10.1017/sus.2020.34

Geist, H. J. and Lambin, E. F. (2002). Proximate causes and underlying driving forces of tropical deforestation: Tropical forests are disappearing as the result of many pressures, both local and regional, acting in various combinations in different geographical locations. BioScience, 52(2), 143-50. https://doi.org/10.1641/o0063568(2002)052[0143:pcaudf]2.0.co;2

Harris, N. L., Gibbs, D. A., Baccini, A., Birdsey, R. A., De Bruin, S., Farina, M., ... and Tyukavina, A. (2021). Global maps of twenty-first century forest carbon fluxes. Nature Climate Change, 11(3), 234-40. https://doi.org/10.1038/s41558-020-00976-6

Ilachinski, A. (2001). Cellular automata - a discrete universe. World Scientific Publishing Company.

Instituto de Pesquisa Ambiental da Amazônia. (2021). Slowing deforestation in the Brazilian Amazon: Avoiding legal deforestation by compensating producers [paper submitted for publication].

International Policy Centre for Inclusive Growth, Institute for Applied Economic Research and Environmental Defense Fund. (2019). International seminar business opportunities for a sustainable rural economy: The contribution from forests and agriculture. International Policy Centre for Inclusive Growth.

https://ipcig.org/publication/29137 
Islam, K. and Sato, N. (2012). Deforestation, land conversion and illegal logging in Bangladesh: The case of the Sal (Shorea robusta) forests. iForest-Biogeosciences and Forestry, 5(3), 171. https://doi.org/10.3832/iforo578-005

Ke, G., Meng, Q., Finley, T., Wang, T., Chen, W., Ma, W., ... and Liu, T. Y. (2017). LightGBM: A highly efficient gradient boosting decision tree. Advances in Neural Information Processing Systems, 30, 3146-54.

Kissinger, G., Herold, M. and De Sy, V. (2012). Drivers of deforestation and forest degradation: A synthesis report for REDD+ policymakers. Lexene Consulting. https://www.cifor.org/knowledge/publication/5167

Mendelsohn, R. (1994). Property rights and tropical deforestation. Oxford Economic Papers, 46, 750-56. https://doi.org/10.1093/oep/46.Supplement_1.750

Meyer, A. L., Van Kooten, G. C. and Wang, S. (2003). Institutional, social and economic roots of deforestation: A cross-country comparison. International Forestry Review, 5(1), 29-37.

Müller-Hansen, F., Heitzig, J., Donges, J. F., Cardoso, M. F., Dalla-Nora, E. L., Andrade, P., ... and Thonicke, K. (2019). Can intensification of cattle ranching reduce deforestation in the Amazon? Insights from an agent-based social-ecological model. Ecological Economics, 159, 198-211. https://doi.org/10.1016/j.ecolecon.2018.12.025

Parsons, J. A. and Fonstad, M. A. (2007). A cellular automata model of surface water flow. Hydrological Processes: An International Journal, 21(16), 2189-95. https://doi.org/10.1002/hyp.6587

Schwartzman, S., Lubowski, R. N., Pacala, S. W., Keohane, N. O., Kerr, S., Oppenheimer, M. and Hamburg, S. P. (2021). Environmental integrity of emissions reductions depends on scale and systemic changes, not sector of origin. Environmental Research Letters, 16(9), 091001.

Sirakoulis, G. C., Karafyllidis, I. and Thanailakis, A. (2000). A cellular automaton model for the effects of population movement and vaccination on epidemic propagation. Ecological Modelling, 133(3), 209-23. https://doi.org/10.1016/So304-3800(oo)00294-5

Soares-Filho, B. S., Cerqueira, G. C. and Pennachin, C. L. (2002). DINAMICA - a stochastic cellular automata model designed to simulate the landscape dynamics in an Amazonian colonization frontier. Ecological Modelling, 154(3), 217-35. https://doi.org/10.1016/So304-380o(02)ooo59-5

Sonter, L. J., Herrera, D., Barrett, D. J., Galford, G. L., Moran, C. J. and Soares-Filho, B. S. (2017). Mining drives extensive deforestation in the Brazilian Amazon. Nature Communications, 8(1), 1-7. https://doi.org/10.1038/s41467-017-00557-w.

Trucchia, A., Egorova, V., Butenko, A., Kaur, I. and Pagnini, G. (2019). RandomFront 2.3: A physical parameterisation of fire spotting for operational fire spread models - implementation in WRF-SFIRE and response analysis with LSFire+. Geoscientific Model Development, 12(1), 69-87. https://doi.org/10.5194/gmd12-69-2019

Tumusiime, D. M., Byakagaba, P. and Tweheyo, M. (2018). Policy and institutional drivers of deforestation. Environmental Policy and Law, 2, 137-44. http://dx.doi.org.proxygt-law.wrlc.org/10.3233/EPL-180065

Verified Carbon Standard. (2011). AFOLU Non-Permanence Risk Tool v.3.o. Verra. https://verra.org/wpcontent/uploads/2018/03/AFOLU Non-Permanence Risk Tool v3.3.pdf 
West, T. A., Börner, J. and Fearnside, P. M. (2019). Climatic benefits from the 2006-2017 avoided deforestation in Amazonian Brazil. Frontiers in Forests and Global Change, 2, 52.

https://www.frontiersin.org/article/10.3389/ffgc.2019.00052

West, T. A., Börner, J., Sills, E. O. and Kontoleon, A. (2020). Overstated carbon emission reductions from voluntary REDD+ projects in the Brazilian Amazon. Proceedings of the National Academy of Sciences, 117(39), $24188-94$.

Environmental Defense Fund 257 ParkAvenue South

New York, NY 10010
T 2125052100 EDF.ORG
New York, NY/Austin, TX/Bentonville, AR / Boston, MA/Boulder, CO/Raleigh, NC/ Sacramento,CA/San Francisco, CA/Washington, DC/Beijing,China/La Paz, Mexico/ London, UK 